\title{
Loneliness in Adolescents: A Flash Survey through Smartphones
}

\author{
Diego de Leo" ${ }^{1,2}$, Manuela Berardinelli3 ${ }^{3}$ Osvaldo Scarpino4, Marco Trabucchi ${ }^{5}$ \\ ${ }^{1}$ AISRAP, Griffith University, Brisbane, Australia \\ ${ }^{2}$ Department of Psychology, Primorska University, Koper, Slovenia \\ ${ }^{3}$ Alzheimer Uniti Italia, Roma, Italy \\ ${ }^{4}$ COOSS Marche, Ancona, Italy \\ ${ }^{5}$ Psychopharmacology, Tor Vergata University, Roma, Italy \\ Email: diegodeleol@gma il.com
}

How to cite this paper: de Leo, D., Berardinelli, M., Scarpino, O. and Trabucchi, M. (2019) Loneliness in Adolescents: A Flash Survey through Smartphones. Open Journal of Medical Psychology, 8, 45-52. https://doi.org/10.4236/ojmp.2019.83004

Received: April 17, 2019

Accepted: July 9, 2019

Published: July 12, 2019

Copyright (c) 2019 by author(s) and Scientific Research Publishing Inc. This work is licensed under the Creative Commons Attribution International License (CC BY 4.0).

http://creativecommons.org/licenses/by/4.0/

cc) (†) Open Access

\begin{abstract}
Background: Loneliness has recently jumped to scholars' attention due to a number of longitudinal studies' results, impacting on health and quality of life of individuals, and political activities (such as the appointment of a dedicated ministry in the UK). All of these results have stimulated the need for better knowledge of the phenomenon and their consequences on different gender and age groups. Aim: So far, most of attention has been dedicated to the problem of older adults; however, younger individuals seem to also appear very vulnerable to loneliness. Method: This short communication is meant to open a window on adolescents' feelings of being lonely or socially isolated, and does so through an investigation performed in the context of a conference on the very theme of loneliness. Results: Even at the age group considered in this study (individuals between 14 and 16 years old) loneliness appears to be a frequent problem. The contribution of the Internet and social media to this phenomenon needs to be clarified. Conclusions: Raising awareness on the seriousness of loneliness for an individual's health and wellbeing appears today of paramount importance. Actions need to be taken at different levels to counteract the consequences of loneliness.
\end{abstract}

\section{Keywords}

Loneliness, Social Isolation, Adolescents, Flash Survey, Smartphone

\section{Introduction}

On January 15, 2018, Theresa May government's decided to establish a ministry to combat loneliness in the country. The need arose from the observation that in 
the United Kingdom the Cox Commission ended up counting over 9 million individuals who feel always or frequently lonely. It is the lack of relationships, contacts and information opportunities that makes this population a group of individuals particularly exposed to the morbidity of all kinds, and therefore exposes the UK government to relevant health costs, calculated by the Consumer Cooperatives (CO-OP) in around 3.5 billion pounds a year.

Many other governments followed the example of Theresa May and formally set up initiatives to help lonely and isolated citizens [1]. However, the type of loneliness we judge as the most important is not synonymous with social isolation or living alone. Cacioppo provided an operational definition of loneliness that is particularly useful for clinical research and planning of interventions. $\mathrm{He}$ suggested that the core concept of loneliness describes a negative emotional state experienced when there is a difference between the relationships one would like to have and those that one perceives to actually have [2]. Following this perspective, the unpleasant sensations of loneliness are therefore subjective. Loneliness is not about the amount of time spent with other people or alone: loneliness is more related to the quality of relationships than to their quantity. "Lonely" persons feel that they are not understood by others, and therefore think they cannot have satisfactory relationships with anyone [2].

\section{Loneliness as a Risk Factor}

The effects of loneliness are not limited to subjective experiences. It is now clear that loneliness is an important risk factor for many problems of physical health, from fragmented sleep and decreased cardiac output to the onset of dementia. The lack of social connections poses a risk of premature death that is very similar to well-known pre-mortality factors such as smoking and obesity [3]. Data of this nature begin to peep out in the scientific limelight in the late 70s, with the publication of the findings of the longitudinal study of the County of Alameda, in California. Berkman and Syme [4], studying about 7000 people, discovered that men and women "disconnected from others" were about three times more likely to die during the study (which lasted nine years) than people with strong social ties.

A few years later (1984), Ruberman and associates [5], studying 2320 male subjects who survived a myocardial infarction, found that people with stronger social connections had much greater odds of staying alive in the three years following the attack than those who could not enjoy the availability of satisfactory social relationships. By conducting a meta analysis of published studies, Holt-Lunstad et al. [6] confirmed that people who have strong social interactions are 50\% more likely to live longer than those with few or absent social ties.

Perissinotto et al. [7], on a sample of 1600 older adults, showed that $43 \%$ of the elderly lived in a lonely condition. Six years after the first interview, the researchers found that those who reported a condition of loneliness had a risk of dying $45 \%$ higher than others; moreover, these people with the sharpening of the 
perception of their own isolation were more exposed to deterioration in their quality of life and reduction in personal autonomy.

The association between loneliness and suicide has long been known [8]. Feelings of non-appartenance to any environment (thwarted belongingness) represent a pivotal concept in the interpersonal theory of suicide [9]. An Australian study of elderly people who died by suicide [8] dramatically highlighted that among the decedents the presence of insufficient social support (from family and/or friends) was almost constantly recorded. In this study, the lack of social support was significantly more important than the lack of practical help from the same sources [8].

\section{Loneliness, Gender and Age}

There are no precise indications on the prevalence of loneliness between the sexes. Living longer than men, it is likely that women may suffer more than them; however, it is well known that women are abler than men in creating relational networks and deriving from them information useful to improve their quality of life and obtain psychological support in case of need. Men are generally less likely to reveal their loneliness because of cultural and gender differences in the expression of emotions [10].

In all western societies, older adults are those who suffer most from loneliness. In Italy, the ISTAT 2018 Report paints a particularly alarming picture: about $40 \%$ of those with $75+$ years of age do not have a friend or a relative to turn to in case of need. Only one elderly person in four has a social network made up of relatives and friends and/or neighbours [11].

With aging, relational opportunities diminish. Various factors contribute to creating the basis for isolation: loss of the social role, progressive disengagement from the active world, diminished economic resources, bereavement from multiple losses, diminished physical capacity, sensory losses, chronic illnesses, and so on. Especially in late life, older adults end up suffering more than other age groups for the consequences of loneliness [12].

\section{A Longitudinal Study among Young People}

A recent study tried to build a detailed and integrative profile of the correlations of feelings of loneliness of young adults, in terms of current health and functioning, comparing them with their experiences and childhood circumstances. Data were taken from the "Environmental Risk Longitudinal Twin Study", a cohort of 2232 individuals born in England and Wales in 1994 and 1995. Loneliness was measured when the participants were 18 years old [13].

Results showed that young people with more feelings of loneliness were also more likely to experience mental health problems, to commit themselves to risky behaviours for physical health more frequently, and to use more negative strategies to cope with stress. As children, these young people were more likely to have encountered mental health problems and to have experienced episodes of bully- 
ing and social isolation. Loneliness did not appear to be related to socio-economic aspects and backgrounds [14].

\section{Hikikomori}

Hikikomori designates a phenomenon involving adolescents or young adults who withdraw from social life, often in search of extreme degrees of isolation. These subjects spend most of their time at home, in their own room, avoiding all social contacts; in most extreme cases people remain isolated for years or even decades. The phenomenon would now affect millions of young individuals around the world. According to Ricci, the hikikomori should not be confused with Internet-dependent subjects; only in a minority of cases which are estimated at around $30 \%$, the hikikomori would use the Internet assiduously; this in order to avoid as far as possible any form of social contact, even if only virtual [14].

Globally, data about the prevalence of loneliness in adolescents appear as very limited [15]. The few examples mostly targeted the relationship between Internet addiction and loneliness [16] [17]. Data on the loneliness of early adolescents are virtually missing, as recently pointed out by Nowland and co-workers [18]. Data on Italian adolescents' loneliness have yet to be published. The aim of the present study was to verify the prevalence and perception of loneliness (according to the definition expressed by Cacioppo and his team) among a sample of high school students of Macerata, central Italy.

\section{Method}

A public conference on the theme of loneliness (on 8 March 2019), which witnessed the attendance of 240 high school students, provided the opportunity for the observations here presented. After a series of formal presentations by qualified speakers, students from various classes (94 females and 146 males), aged between 14 - 16 years old, were invited to answer a series of questions through Google Form with the aid of their smartphones and via the internal Wi-Fi connection. Participation was non-compulsory, and students were allowed to remain anonymous. The accompanying teachers granted permission for students' participation in the survey.

The Three-Item Loneliness Scale [19], as shown in Table 1, was first administered to students.

Seven questions were then posed to students: 1) Do you spend more than four hours a day on social networks? 2) In your case, did contacts through social networks substitute "traditional" contacts (face-to-face)? 3) When you have a personal problem, do you immediately know to whom to refer to? 4) In your view, can loneliness make people sick? 5) Do you often feel lonely? 6) Did you ever feel socially isolated? And, 7) Do you think it would be wiser to speak more face-to-face and less through computers, thus recuperating the sense of belonging to a real community and not to a virtual one? Students were given about 15 minutes to answer the seven questions and ten minutes to answer the three-item loneliness scale. 
Table 1. The three-item loneliness scale.

\begin{tabular}{cccc}
\hline Question & Never & Sometimes & Often \\
\hline First, how often do you feel that you lack companionship? & 1 & 2 & 3 \\
How often do you feel left out? & 1 & 2 & 3 \\
How often do you feel isolated from others? & 1 & 2 & 3 \\
\hline
\end{tabular}

\section{Results}

There were no students scoring 3 or 4 points at the three-item loneliness scale. This means that all 240 students felt some form of loneliness sometimes or often. More precisely, 48 students (20.0\%) scored 5, and 113 (47.1\%) 6 points, indicating that, globally, a bit more than two third of students "sometimes" do feel lonely. Thirty-eight students (15.8\%) scored 7 points; 31 (12.9\%) scored 8 and 10 students (4.2\%) scored 9. This means that approximately one third of the students feels quite often lonely (chi-square 8.42, df2, p < 0.025).

All students answered question \#1 (Do you spend more than four hours a day on social networks?). $48.3 \%$ of them answered "Yes", and 51.7\% "No" to this question. After question \#1, more than forty students did not continue answering the remaining questions.

Nearly thirty percent of students $(28.7 \%)$ said that social media have substituted face-to-face contacts (question \#2; valid answers: $\mathrm{n}=195$ ). More than $4 / 5$ (81\%) said that they do actually have someone to talk to in case of troubles (question \#3; valid answers: $\mathrm{n}=195$ ). An even higher percentage $(85.1 \%)$ thought that loneliness could really provoke diseases (question \#4; valid answers $\mathrm{n}=194$ ). About one fourth of young students (24\%) do often feel lonely (question \#5, valid answers $n=196$ ) but $41 \%$ have also felt socially isolated on a few occasions (question \#6; valid answers $\mathrm{n}=196$ ). Finally, most people would like to chat less through computers and meet face-to-face more frequently (92.4\%) (question \#7; valid answers $\mathrm{n}=197$ ) (Table 2).

If we consider that 41 students $(31+10)$ out of the 240 reported the highest scores at the three-item loneliness scale (being the most lonely), this finding matches well with the $24 \%$ of the 196 remaining students (corresponding to 46 individuals) that answered question \#5 saying that they often feel lonely. This holds true also for those who felt socially isolated a few times (question \#6): 80 students out of 196 versus 79 out of 240 that answered the three-item scale on loneliness.

Most students did not indicate their sex and so it was not possible to further discriminate between answers from males and females.

\section{Discussion}

This short and descriptive communication evidences the existence of feelings of loneliness also in very young individuals. Even at an age in which socializing should be very easy and opportunities for friendship and companionship very numerous, between one quarter and one third of this sample of students often 
Table 2. Questions on the use of Internet and feelings of loneliness.

\begin{tabular}{|c|c|c|}
\hline $\begin{array}{l}\text { 1) Do you spend more than four hours a day on social } \\
\text { networks? }(\mathrm{n}=240)\end{array}$ & YES & $48.3 \%$ \\
\hline $\begin{array}{l}\text { 2) In your case, did contacts through social networks subs- } \\
\text { titute 'traditional' contacts (face-to-face)? }(\mathrm{n}=195)\end{array}$ & YES & $28.7 \%$ \\
\hline $\begin{array}{l}\text { 3) When you have a personal problem, do you immediate- } \\
\text { ly know to whom to refer to? }(\mathrm{n}=195)\end{array}$ & YES & $81.0 \%$ \\
\hline 4) In your view, can loneliness make people sick? $(\mathrm{n}=194)$ & YES & $85.1 \%$ \\
\hline 5) Do you often feel lonely? $(n=196)$ & YES & $24.0 \%$ \\
\hline 6) Did you ever feel socially isolated? & YES & $41.0 \%$ \\
\hline $\begin{array}{l}\text { 7) Do you think it would be wiser to speak more } \\
\text { face-to-face and less through computers, thus recuperating } \\
\text { the sense of belonging to a real community and not to a } \\
\text { virtual one? }(n=197)\end{array}$ & YES & $92.4 \%$ \\
\hline
\end{tabular}

feel lonely and more than forty percent at some stage have felt socially isolated. These are worrisome percentages that underline the problem of loneliness also in adolescents. It is noteworthy that a large majority of them feel the need for person-to-person contacts instead of communications via social media. Moreover, it is equally of concern that almost half of them spend more than four hours per day on social networks. Considering the amount of time involved in attendance to classrooms and homework, the remaining time spent in interactions with family members and sport and leisure activities appear globally quite limited. In addition, people continue to increase their time on the Internet [20], with young individuals spending not only time on social networks [18] but also on games, information and other topics, making of computers and smartphones most of their days [20].

It is also of notice that students seem to be already aware of the dangers involved with feeling lonely since most of them consider this condition capable of making individuals sick. The use of social media is constantly growing especially among young adults and, despite these greater interconnections, it seems that the current generation is the most solitary or lonely of all time. The quality of relationships, as Cacioppo and Cacioppo claimed [2], seems to be the only real defense against unpleasant or painful experiences.

Assuming that diffusion and popularity of social networks will continue to increase, the problem of loneliness may reach disturbing dimensions also in adolescence, possibly creating the grounds for a generation of individuals less used than before to the human touch and intimacy. How this will interfere with well-being and quality of life of this individual in the course of their life remains a puzzling perspective.

The simple observations here reported obviously suffer from several shortcomings. The sample of convenience constituted by the young students was brought to attend the conference by the accompanying teachers. It is possible that not all students were really motivated to attend; in fact, while all students answered the three-item loneliness scale and the first question, a bit more than 
forty of them quitted the room and did not continue the survey. In addition, the way the flash survey was organized made not possible to identify age-subgroups or gender-related answers. Likewise, no information was obtainable about participants' background, family composition and social connections.

\section{Conclusions}

The study of loneliness still appears in its infancy. As a "transversal" element, which concerns different fields such as, for example, psychology, medicine, sociology and anthropology, the study of loneliness risks suffering from the schematic borders of funding agencies to slow down any development. The literature data available are still few; among them, there is still much confusion between apparently overlapping concepts such as social isolation, being alone and suffering from loneliness.

Raising awareness on the problem of loneliness appears today of primary importance. Adolescents do not seem immune to this condition. The unpretentious nature of the observations here reported on a sample of Italian high school students evidence that the problem is present also early in the life of traditionally hyper-protected youngsters from a country such as Italy. The increasing use of electronic devices and social networks is destined to deeply modify structures and values of next societies in ways very difficult to predict, given the rapidity of changes. However, for the time being, it is compulsory to raise awareness among public opinion and health workers on the need for appropriate interventions to counteract the seriousness of the phenomenon of loneliness in its many aspects and repercussions. Parents and teachers may have a role in educating young individuals to the importance of social relationships and especially of friendships. The use of the social Internet should be monitored and guided so that it does not end by substituting interpersonal contacts with the virtual ones.

\section{Conflicts of Interest}

The authors declare no conflicts of interest regarding the publication of this paper.

\section{References}

[1] De Leo, D. and Trabucchi, M. (2019) Loneliness Is the Enemy. Analyses and Proposals to Contrast Loneliness in Old Age. Il Poligrafo, Padova.

[2] Cacioppo, J.T. and Cacioppo, S. (2014) Social Relationships and Health: The Toxic Effect of Perceived Social Isolation. Social and Personality Psychology Compass, 8, 58-72. https://doi.org/10.1111/spc3.12087

[3] Cacioppo, J.T. and Patrick, W. (2008) Loneliness: Human Nature and the Need for Social Connection. W.W. Norton \& Company, New York.

[4] Berkman, L.F. and Syme, S.L. (1979) Social Networks, Host Resistance, and Mortality: A Nine-Year Follow-Up Study of Alameda County Residents. American Journal of Epidemiology, 109, 186-204. https://doi.org/10.1093/oxfordjournals.aje.a112674

[5] Ruberman, W., Weinblatt, E., Goldberg, J.D. and Chaudary, B.S. (1984) Psychoso- 
cial Influences on Mortality after Myocardial Infarction. New England Journal of Medicine, 311, 552-559. https://doi.org/10.1056/NEJM198408303110902

[6] Holt-Lunstad, J., Smith, T. and Layton, J. (2010) Social Relationships and Mortality Risk: A Meta-Analytic Review. PLoS Medicine, 7, e1000316.

https://doi.org/10.1371/journal.pmed.1000316

[7] Perissinotto, C.M., Stijacic Cenzer, I. and Covinsky, K.E. (2012) Loneliness in Older Persons: A Predictor of Functional Decline and Death. Archives of Internal Medicine, 172, 1078-1083. https://doi.org/10.1001/archinternmed.2012.1993

[8] De Leo, D., Draper, B., Snowdon, J. and Kolves, K. (2013) Suicides in Older Adults: A Case-Control Psychological Autopsy Study in Australia. Journal of Psychiatric Research, 47, 980-988. https://doi.org/10.1016/j.jpsychires.2013.02.009

[9] Van Orden, K.A., Witte, T.K., Cukrowicz, K.C., Braithwaite, S.R., Selby, E.A. and Joiner, T.E. (2010) The Interpersonal Theory of Suicide. Psychological Review, 117, 575-600. https://doi.org/10.1037/a0018697

[10] Franklin, A., Neves, B.B., Hookway, N., Patulny, R., Tranter, B. and Jaworski, K. (2018) Towards an Understanding of Loneliness among Australian Men: Gender Cultures, Embodied Expression and the Social Bases of Belonging. Journal of Sociology, 55, 124-143. https://doi.org/10.1177/1440783318777309

[11] ISTAT (2018) 2018 Report. National Institute of Statistics, Rome.

[12] Holwerda, T.J., Beekman, A.T.F., Deeg, D.J.H., et al. (2012) Increased Risk of Mortality Associated with Social Isolation in Older Men: Only When Feeling Lonely? Results from the Amsterdam Study of the Elderly (AMSTEL). Psychological Medicine, 42, 843-853. https://doi.org/10.1017/S0033291711001772

[13] Matthews, T., Danese, A., Caspi, A., Fisher, H.L., Goldman-Mellor, S., Kepa, A., Moffitt, T.E., Odgers, C.L. and Arseneault, L. (2019) Lonely Young Adults in Modern Britain: Findings from an Epidemiological Cohort Study. Psychological Medicine, 49, 268-277. https://doi.org/10.1017/S0033291718000788

[14] Ricci, C. (2008) Hikikomori: Adolescents in Voluntary Seclusion. Franco Angeli, Milano.

[15] Van Roekel, E., Scholte, R.H.J., Engels, R.M.E., Goossens, L. and Verhagen, M. (2014) Loneliness in the Daily Lives of Adolescents: An Experience Sampling Study Examining the Effects of Social Contexts. Journal of Early Adolescence, 35, 905-930. https://doi.org/10.1177/0272431614547049

[16] Subrahmanyam, K. and Lin, G. (2007) Adolescence on the Net: Internet Use and Well-Being. Adolescence, 42, 659-677.

[17] Koyuncu, T., Unsal, A. and Arslantas, D. (2014) Assessment of Internet Addiction and Loneliness in Secondary and High School Students. Journal of Pakistan Medical Association, 64, 998-1002.

[18] Nowland, R., Necka, E.A. and Cacioppo, J.T. (2018) Loneliness and Social Internet Use: Pathways to Reconnection in a Digital World. Perspectives on Psychological Science, 13, 70-87. https://doi.org/10.1177/1745691617713052

[19] Hughes, M.E., Waite, L.J., Hawkley, L.C. and Cacioppo, J.T. (2004) A Short Scale for Measuring Loneliness in Large Surveys. Results from Two Population-Based Studies. Research on Aging, 26, 655-672. https://doi.org/10.1177/0164027504268574

[20] Lebo, H. (2017) The 2017 Digital Future Report. University of Southern California, Los Angeles. 